Instructions/Template for Preparing Manuscript for Jendela Nursing Journal

\title{
Pengaruh Pendidikan Kesehatan terhadap Pengetahuan dan Perilaku Orangtua tentang Pencegahan Resiko Kekambuhan Sesak Napas Asma Anak
}

\author{
Boediarsih $^{1}$, Istiana Nur Aini ${ }^{1}$, Sawitry ${ }^{1}$ \\ ${ }^{I}$ Jurusan Keperawatan, Sekolah Tinggi Ilmu Kesehatan Karya Husada \\ Coresponding Author: boediarsih@stikesyahoedsmg.ac.id
}

\begin{abstract}
Background: Asthma is a chronic respiratory disease with an increasing prevalence in children and adults since the last two decades. So that it becomes the cause of morbidity and mortality.

Purpose: To analyze the effect of health education on knowledge and behavior of parents about preventing the risk of recurrence of asthma in children in Balkesmas, Ambarawa Region.

Methods: The research used was quantitative descriptive with purposive sampling technique. The population of this study was 64 samples with health education intervention and analyzed to determine the effect of the research results.

Results: Based on an analysis using the Wilcoxon signed rank test obtained $p$ value is worth $0.000(<0.05)$, it can be concluded that there are changes in knowledge and behavior before and after in doing health education measures. There is an effect of health education with the knowledge of the parents of children with asthma with a $p$ value of 0.000 . There is an effect of health education on the behavior of the parents of children with asthma with a $p$ value of 0.000 .

Conclusion: It is hoped that the results of this study can be used as a method of preventing recurrence of child asthma shortness of breath, by providing health education to parentsthus reducing dependence on drugs.
\end{abstract}

\section{Keywords:}

Child Asma, Health Education, Knowledge, Parents

\section{LATAR BELAKANG}

Asma merupakan salah satu penyakit pernapasan kronis dengan prevalensi yang meningkat pada anak maupun dewasa sejak dua dekade terakhir(Damanik, Sutomo and Setyati, 2016). Penyakit saluran pernapasan ini paling sering menyerang usia anak dan masih tetap merupakan masalah utama bagi pasien, keluarga, bahkan para klinisi dan peneliti(Akib, 2016). Menurut World Health Organization memperkirakan 100-150 juta penduduk dunia saat ini terkena penyakit asma dan diperkirakan akan mengalami penambahan 180.000 setiap tahunnya(Dharmayanti, Hapsari and Azhar, 2015) Data epidemiologi Amerika Serikat pada saat ini diperkirakan terdapat 4-7\% (4,8 juta anak) 
dari seluruh populasi asma. Menurut para ahli, prevalensi asma akan terus meningkat. Asma tidak bisa disembuhkan, akan tetapi dengan penanganan yang tepat penyakit ini bisa dikontrol agar kualitas hidup penderita dapat terjaga. Gejala klinis asma sangat khas yaitu sesak napas berulang dan suara mengi (wheezing) akan tetapi gejala ini bervariasi pada setiap individu, berdasarkan tingkat keparahan dan frekuensi kekambuhannya(Dharmayanti, Hapsari and Azhar, 2015). Gejala lain adalah batuk produktif yang memburuk terutama pada malam hari atau menjelang pagi, dan dada terasa tertekan. Dikatakan asma, apabila penderita pernah mengalami sesak napas yang terjadi bila terpapar langsung oleh satu atau lebih dari pemicu (allergen) misalnya makanan, udara dingin, stres, flu, kelelahan, alergi obat debu, asap rokok dan faktor pemicu lainnya(Dharmayanti, Hapsari and Azhar, 2015).

Menurut data Kemenkes RI di tahun 2018 menyatakan penyakit asma masuk dalam sepuluh besar penyebab kesakitan dan kematian. Angka kejadian asma 80\% terjadi di negara berkembang akibat kemiskinan, kurangnya tingkat pendidikan, pengetahuan dan fasilitas pengobatan(Menteri Kesehatan Republik Indonesia, 2018). Angka kematian yang disebabkan oleh penyakit asma diperkirakan akan meningkat 20\% untuk sepuluh tahun mendatang, jika tidak terkontrol dengan baik. Di Provinsi Jawa Tengah prevalensi kasus asma pada tahun 2018 sebesar 1\% dengan prevalensi tertinggi di daerah Surakarta(Menteri Kesehatan Republik Indonesia, 2018).

Usaha untuk menjaga agar tidak kambuh juga bergantung pada pengetahuan klien terhadap penyakitnya, karena dengan pengetahuannya tersebut klien memiliki alasan dan landasan untuk menentukan suatu pilihan. Informasi dan pengetahuan tentang asma sangat penting diajarkan kepada pasien adalah mengenal faktor pemicu serangan asma pada dirinya serta pemahaman tentang pencegahan, perawatan dan kerja obat asma. Tingkat pengetahuan yang baik mempengaruhi frekuensi kekambuhan, karena dengan pengetahuan yang baik penderita mampu melakukan pencegahan kekambuhan yang berulang(Astuti and Darliana, 2018).

Berdasarkan data laporan bulanan indeks penyakit di klinik umum anak selama 3 tahun terakhir di Balkesmas Wilayah Ambarawa didapatkan bahwa prevalensi penyakit asma pada tahun 2016 ditemukan kejadian kekambuhan sebanyak 951 dari 1840 kunjungan, sedangkan laporan tahun 2017 mencatat angka kekambuhan penyakit asma sebanyak 401 penderita dari total 828 kunjungan. Tahun 2018 mencatat angka kekambuhan asma sebanyak 848 dari total kunjungan 1564 penderita asma anak, sedangkan di tahun 2019 angka kekambuhan asma sebanyak 642 kasus dengan total kunjungan sebanyak 1234 pasien asma anak. Angka kejadian asma anak termasuk 10 besar penyakit dari jumlah pasien yang berobat di klinik umum anak di Balkesmas Wilayah Ambarawa dengan prevalensi terbanyak adalah umur 3-5 tahun. Penanganan awal yang dilakukan di klinik anak adalah terapi inhaler, nebulizer dan postural drainase disertai infrared. Namun hal ini ternyata kurang efektif mengurangi angka kekambuhan sesak nafas pada asma anak. Kendala lain adalah tindakan medis yang diberikan tidak disertai dengan pemberian pendidikan kesehatan terhadap orangtua terkait sesak nafas pada asma anak.

Berdasarkan observasi awal yang dilakukan oleh penulis selama bertugas di klinik umum anak Balkesmas Wilayah Ambarawa, menunjukkan bahwa pasien asma anak sering mengalami kekambuhan sesak napas yang berulang dan lebih hebat. Orangtua 
mengatakan tidak mengetahui penyebab kambuhnya sesak napas bahkan disertai batuk dan demam. Penyebab lain adalah orangtua tidak mampu mengenali hal-hal yang memicu sesak napas pada asma anak. Berdasarkan hasil wawancara penulis pada 10 orangtua yang anaknya terkena asma menunjukkan bahwa pasien asma anak masih sering berperilaku memakan makanan yang mengandung allergen, tidak menjaga kebersihan lingkungan, tidur dilantai tanpa selimut dengan kipas angin yang berdebu, dan perilaku aktifitas tanpa istirahat. Oleh sebab itu peran pendidikan kesehatan pada pasien dan keluarga merupakan unsur penting penatalaksanaan asma pada anak yang bertujuan untuk meminimalkan morbiditas fisik dan psikis serta mencegah disabilitas(Akib, 2016)

\section{METODE}

Pendekatan yang digunakan dalam penelitian ini adalah pendekatan kuantitatif diskriptif yang berusaha membuktikan hipotesis dengan analisis statistik. Jenis penelitian yang digunakan adalah penelitian eksperimen. Desain Penelitian ini menggunakan pendekatan quasi eksperimental design. Penelitian ini termasuk One Group Pre TestPost Test Design, yaitu melakukan satu kali pengukuran didepan (pre test) sebelum adanya perlakuan (treatment) dan setelah itu dilakukan pengukuran lagi (post test).

\section{HASIL}

Tabel 1. Skor pengetahuan dan perilaku sebelum pendidikan kesehatan

\begin{tabular}{llllll}
\hline Variabel & $\mathrm{N}$ & Median & Min & Max & Std. Deviation \\
\hline Pengetahuan & 64 & 17.0000 & 14.00 & 19.00 & \pm 1.51054 \\
Perilaku & 64 & 12.5000 & 10.00 & 14.00 & \pm 1.34436 \\
\hline
\end{tabular}

Hasil penelitian pada tabel 1 menunjukan bahwa skor pengetahuan sebelum perlakuan pendidikan kesehatan rata-rata adalah 17.0000 , standar deviasi \pm 1.51054 , dengan skor pengetahuan terendah 14.00 dan tertinggi 19.00. Hasil penelitian pada tabel 1 menunjukan bahwa skor perilaku sebelum perlakuan pendidikan kesehatan rata-rata adalah 12.5000 , standar deviasi \pm 1.34436 dengan skor terendah 10.00 dan tertinggi 14.00 .

Tabel 2. Skor pengetahuan dan perilaku sesudah pendidikan kesehatan

\begin{tabular}{lccccc}
\hline Variabel & $\mathrm{N}$ & Median & Min & Max & Std. Deviation \\
\hline $\begin{array}{l}\text { Pengetahuan } \\
\text { Perilaku }\end{array}$ & 64 & 18.0000 & 16.00 & 20.00 & \pm 0.89296 \\
& 64 & 12.0000 & 11.00 & 14.00 & \pm 0.90633 \\
\hline
\end{tabular}

Hasil penelitian pada tabel 2 menunjukan bahwa skor pengetahuan sesudah perlakuan pendidikan kesehatan rata-rata pada skor 18.0000, standar deviasi 
\pm 0.89296 , dengan skor pengetahuan terendah 16,00 dan tertinggi 19,00. Hasil penelitian pada tabel 2 menunjukan bahwa skor perilaku sesudah perlakuan pendidikan kesehatan rata-rata adalah 12.0000 , standar deviasi \pm 0.90633 dengan skor terendah 11,00 dan tertinggi 14,00

Dari hasil analisis normalitas data diketahui bahwa pada variabel pengetahuan dan perilaku sebelum dan sesudah dilakukan pendidikan kesehatanmemiliki distribusi data yang tidak normal dengan $p$-value $<0,05$, sehingga dalam pemilihan uji beda dua variabel berhubungan yang berdistribusi tidak normal adalah uji wilcoxon.

Tabel 3. uji wilcoxon pengetahuan sebelum dan sesudah pendidikan kesehatan

\begin{tabular}{|c|c|c|c|c|c|c|}
\hline \multirow{3}{*}{$\begin{array}{l}\text { Pengetahuan } \\
\text { sebelum - } \\
\text { sesudah } \\
\text { pendidikan } \\
\text { kesehatan }\end{array}$} & $\mathrm{N}$ & Median & Std. & Min. & $\operatorname{Max}$ & $\mathrm{P}$-value \\
\hline & 64 & 17.0000 & \pm 1.51054 & 14.00 & 19.00 & 0,000 \\
\hline & & 18.0000 & \pm 0.89296 & 16.00 & 20.00 & \\
\hline
\end{tabular}

Tabel 4.uji wilcoxon perilaku sebelum dan sesudah pendidikan kesehatan

\begin{tabular}{lcccccc}
\hline $\begin{array}{l}\text { Perilaku sebelum } \\
\text { dan sesudah }\end{array}$ & $\mathrm{N}$ & Median & Std. Deviation & Min. & Max & 0,000 \\
\cline { 2 - 6 } $\begin{array}{l}\text { pendidikan } \\
\text { kesehatan }\end{array}$ & 64 & 12.5000 & \pm 1.34436 & 10.00 & 14.00 & 0,000 \\
& & 13.0000 & \pm 0.90633 & 11.00 & 14.00 & \\
\hline
\end{tabular}

Berdasarkan analisa bivariate dengan menggunakan Uji Wilcoxon didapatkan $p$ value bernilai $0,000 \quad(<0,05)$, maka dapat disimpulkan bahwa terdapat perubahan pengetahuan dan perilaku sebelum dilakukan dan sesudah di lakukan tindakan pendidikan kesehatan. Hal ini berarti Ho ditolak Ha di terima, dengan demikian dapat disimpulkan ada perbedaan sebelum dan sesudah dilakukan pendidikan kesehatan terhadap perubahan pengetahuan dan perilaku orangtua asma anak di Balkesmas Wilayah Ambarawa.

\section{PEMBAHASAN}

Berdasarkan hasil penelitian diketahui bahwa dari 64 responden pada pre-test atau sebelum diberikan pendidikan kesehatan tentang pencegahan resiko kekambuhan sesak napas pada anak bahwa tingkat pengetahuan orangtua mempunyai nilai median 17.000 dan Standar Deviasi \pm 1.51054 dengan nilai minimum 14.00 dan nilai maksimum 19.00 . Nilai ini menggambarkan bahwa tingkat pengetahuan orangtua kurang karena kedua orangtua bekerja yang jarang mengikuti kegiatan yang berhubungan dengan penyakit penyakit asma. Dari hasil data penelitian ada 54 responden yang bekerja. Hal ini berdampak pada frekuensi kekambuhan sesak napas pada asma meningkat serta orangtua tidak maksimal dalam mengontrol sesak napas pada asma anak. Hal ini sesuai 
dengan konsep teori yang mengatakan faktor-faktor yang mempengaruhi pengetahuan salah satunya ada faktor pendidikan,informasi,sosial budaya dan lingkungan.

Pada post test setelah diberikan pendidikan kesehatan upaya pencegahan resiko kekambuhan sesak napas tingkat pengetahuan menjadi berada pada nilai median 18.000 standar deviasi \pm 0.89296 nilai minimum 16.00 nilai maksimum 20.00. Nilai tersebut menunjukkan bahwa pendidikan kesehatan memberikan pengaruh yang sangat baik untuk meningkatkan pengetahuan orangtua dan keluarga pasien asma anak.. Dalam hal ini orangtua paham apabila asma adalah penyakit pada saluran pernapasan yang disebabkan oleh alergi. Pengetahuan yang meningkat menunjukkan bahwa responden memiliki pemahaman yang baik terhadap sesak napas pada asma anak termasuk bagaimana cara menghadapi kekambuhan atau upaya untuk mencegah sesak napas kambuh kembali, ini bisa peneliti lihat saat melakukan pendampingan pasien dalam upaya pencegahan. Hasil penelitian ini mendukung penelitian A.Winangsit bahwa tingkat pengetahuan keluarga dalam memberikan perawatan pada penderita asma sebelum dan sesudah mendapatkan pendidikan kesehatan mempunyai tingkat pengetahuan baik dan cukup dibandingkan sikap keluarga sebelum mendapatakn intervensi pendidikan kesehatan.

Berdasarkan hasil penelitian diketahui bahwa dari 64 responden pada pre test atau sebelum diberikan pendidikan kesehatan pencegahan resiko kekambuhan sesak napas asma anak mempunyai nilai median 12.5000 dengan standar deviasi \pm 1.34436 sedangkan nilai minimal 10.00 dan nilai maksimalnya 14.00 . Nilai ini menunjukkan bahwa perilaku orangtua belum baik dikarenakan karena ketidakmampuan mengenali faktor pencetus kekambuhan sesak napas pada anak , sehingga responden hanya terusmenerus memeriksakan anaknya setiap kali kambuh ke klinik Anak Balkesmas Wilayah Ambarawa. Perilaku yang ditunjukkan hanya sekedar meminumkan obat yang diperoleh dari dokter.

Pada post test setelah diberikan pendidikan kesehatan pencegahan kekambuhan sesak napas pada asma anak perilaku orangtua menjadi lebih baik sebanyak 51 responden dengan nilai median 13.0000 standar deviasi \pm 0.90633 nilai minimum 11.00 dan nilai maksimum 14.00 . Nilai tersebut menunjukkan bahwa pendidikan kesehatan memberikan pengaruh yang sangat baik untuk merubah perilaku orangtua pasien asma anak. Bahwa upaya pencegahan sama pentingnya dengan pengobatan saat sesak napas terjadi. Proses pendidikan kesehatan yang diikuti dapat memberikan pemahaman yang baik terhadap orangtua tentang bagaimana cara menangani dan menghadapi kekambuhan sesak napas pada asma anak.

Menurut Ensiklopedia Amerika perilaku diartikan sebagai suatu reaksi dan aksi organisme terhadap lingkungannya. Perilaku manusia mempunyai pengaruh terhadap status kesehatan individu, kelompok dan masyarakat. Hasil penelitian ini sejalan dengan penelitian Diana Mariana Damanik ${ }^{(1)}$ yang memberikan kesimpulan bahwa adanya peningkatan perilaku setelah diberikan pendidikan kesehatan tentang pencegahan asma dimana peningkatan pengetahuan yang baik mengarah pada kontrol asma sehingga menuju perilaku yang lebih baik. 
Berdasarkan hasil analisis data didapatkan bahwa nilai $p$ value 0,000 karena $p<0,05$ maka dapat disimpulkan bahwa adaPengaruh Pendidikan Kesehatan terhadap Pengetahuan dan Perilaku Orangtua tentang Pencegahan resiko kekambuhan sesak napas pasien asma anak (di Balkesmas Wilayah Ambarawa).Secara teori ketika pendidikan kesehatan baik maka pengetahuan orangtua pasien asma anak juga baik dan berada pada level yang tinggi. Sama seperti dengan penelitian yang dilakukan oleh Astuti. ${ }^{(5)}$ yang menyatakan bahwa pendidikan berpengaruh positif terhadap meningkatnya kualitas dalam pengetahuan. Jadi pengetahuan sangat mutlak untuk dimiliki oleh setiap individu dalam hal ini orangtua asma anak.

Berdasarkan hasil analisis data didapatkan bahwa nilai $p$ value 0,000 karena $p<0,05$ maka dapat disimpulkan bahwaadaPengaruh Pendidikan Kesehatan terhadap Pengetahuan dan Perilaku Orangtua tentang Pencegahan resiko kekambuhan sesak napas pasien asma anak (di Balkesmas Wilayah Ambarawa).Menurut Ensiklopedia Amerika perilaku diartikan sebagai suatu reaksi dan aksi organisme terhadap lingkungannya. Perilaku manusia mempunyai pengaruh terhadap status kesehatan individu, kelompok dan masyarakat. Perilaku itu sendiri adalah suatu yang kompleks, merupakan resultansi dari berbagai macam aspek internal maupun eksternal, psikologis maupun fisik. Oleh karena demikian kompleksnya sehingga diperlukan pemahaman dan analisis yang mendalam ${ }^{(25)}$. Secara teori ketika pendidikan kesehatan itu tinggi maka perilaku orangtua pasien asma anak juga akan baik, tetapi ditemukan beberapa sampel responden menunjukkan bahwa perilaku orangtua pasien asma anak di Balkesmas Wilayah Ambarawa tidak hanya dipengaruhi oleh pendidikan kesehatan saja namun juga dipengaruhi oleh beberapa faktor lain, artinya pendidikan kesehatan bukan satusatunya faktor yang mempengaruhi baik buruknya perilaku seseorang Hasil penelitian ini sejalan dengan penelitian Damanik ${ }^{(1)}$ yang memberikan kesimpulan bahwa ada pengaruh pemberian pendidikan kesehatan tentang pencegahan kekambuhan sesak napas dimana pengetahuan dan sikap yang baik mengarah kepada perilaku yang juga lebih baik.

\section{SIMPULAN}

Ada pengaruh pendidikan kesehatan dengan pengetahuan dan perilaku orangtua pasien asma anak. Hasil penelitian ini dapat menjadi referensi bagi peneliti lain dalam melakukan riset kuantitatif tentang Pendidikan Kesehatan dalam rangka upaya meningkatkan pengetahuan dan perilaku orang tua mengatasi kekambuhan sesak napas pada penderita asma anak.

\section{REFERENSI}

Akib, A. A. (2016) 'Asma pada Anak', Sari Pediatri, 4(2), p. 78. doi: $10.14238 / \mathrm{sp} 4.2 .2002 .78-82$.

Astuti, R. and Darliana, D. (2018) 'Hubungan Pengetahuan Dengan Upaya Pencegahan Kekambuhan Asma Bronkhial', Idea Nursing Journal, 9(1), pp. 9-15.

Damanik, D. M., Sutomo, R. and Setyati, A. (2016) 'Hubungan Asma dengan Gangguan Perilaku pada Anak', Sari Pediatri, 16(6), p. 391. doi: 10.14238/sp16.6.2015.391-6.

Dharmayanti, I., Hapsari, D. and Azhar, K. (2015) 'Asma pada anak Indonesia: Penyebab dan Pencetus', Kesmas: National Public Health Journal, 9(4), p. 320. 
Jendela Nursing Journal, 4(2), 2020,

doi: 10.21109/kesmas.v9i4.738. 